\title{
CYBERBULLYING: MOTIVOS DA AGRESSÃO NA PERSPETIVA DE JOVENS PORTUGUESES*
}

\author{
Ana Paula Caetano ${ }^{1}$ \\ JoÃo AMAdo ${ }^{2}$ \\ Maria José D. Martins ${ }^{3}$ \\ Ana Margarida Veiga Simãó ${ }^{4}$ \\ ISABEL FREIRE ${ }^{1}$ \\ Maria Teresa Ribeiro PessôA ${ }^{5}$
}

\begin{abstract}
RESUMO: Este artigo apresenta parte do estudo do projeto Cyberbullyingum diagnóstico da situação em Portugal*, no qual foi aplicado um questionário a 3.525 adolescentes do $6^{\circ}, 8^{\circ}$ e $11^{\circ}$ níveis de escolaridade para compreender a incidência do fenómeno e analisar os processos associados, nomeadamente os motivos percecionados, objeto específico deste trabalho. Os motivos mais invocados pelos que desempenham o papel de agressor são hedonistas relacionados com brincadeira, diversão e fuga ao tédio, bem como motivos de afiliaçáo e reativos. Os que se identificam como vítimas, por sua vez, atribuem aos seus agressores motivos de afiliação, hedonistas e de poder, com ênfase particular, por ordem decrescente, para a inveja, a diversão, a imaturidade, o ciúme, a falta de respeito, a ausência de afeto e os sentimentos de superioridade.
\end{abstract}

Palavras-chave: Cyberbullying. Vítimas. Agressores. Motivos reativos. Motivos instrumentais.

\footnotetext{
*O artigo é resultado do projeto de pesquisa Cyberbullying: motivos da agressão na perspetiva de jovens portugueses e apresenta parte do estudo do projeto Cyberbullying - um diagnóstico da situaçáo em Portugal, ambos financiados no âmbito do Programa Operacional Temático Fatores de Competitividade (COMPETE) e comparticipado pelo Fundo Comunitário Europeu FEDER e pela Fundação para a Ciência e Tecnologia

${ }^{1}$ Universidade de Lisboa, Instituto de Educação - Lisboa, Portugal. E-mails: apcaetano@ie.ulisboa.pt, isafrei@ie.ulisboa.pt

${ }^{2}$ Universidade de Coimbra, Faculdade de Psicologia e de Ciências da Educação - Coimbra, Portugal.

E-mail: joao.amado@sapo.pt

${ }^{3}$ Escola Superior de Educação do Instituto Politécnico de Portalegre - Portalegre, Portugal. E-mail: mjmartins@esep.pt

${ }^{4}$ Universidade de Lisboa, Faculdade de Psicologia, Centro de Investigação em Ciência Psicológica - Lisboa, Portugal.E-mail:amsimao@psicologia@ulisboa.pt

${ }^{5}$ Universidade de Coimbra, Faculdade de Psicologia e de Ciências da Educação - Coimbra, Portugal.

E-mail: tpessoa@fpce.uc.pt

DOI: 10.1590/ES0101-73302017139852
} 


\title{
CYBERBULLYING: MOTIVES OF AGGRESSION FROM THE PERSPECTIVE OF YOUNG PORTUGUESE
}

\begin{abstract}
This article presents part of the study Cyberbullying project - a diagnosis of the situation in Portugal, in which a questionnaire has been applied to 3,525 adolescents in the $6^{\text {th }}, 8^{\text {th }}$ and $11^{\text {th }}$ levels of education to understand the incidence of the phenomenon and to analyze the processes associated with it, including the motives of the bullies, specific object of this article. As regards the reasons identified, the most relied on by bullies to justify their behavior are hedonistic reasons of joke, fun, escape from boredom as well as motives of affiliation and retaliation. Those who identify themselves as victims attribute to their aggressors motives of affiliation, hedonism and power, with emphasis, in descending order, to envy, fun, immaturity, jealousy, lack of respect, lack of affection and feelings of superiority.
\end{abstract}

Keywords: Cyberbullying. Victims. Bullies. Reactive motives. Instrumental motives.

\section{CYBERBULLYING : LES RAISONS DE L'AGRESSION DU POINT DE VUE DES JeUnes PORTUGaIS}

RESUME: Cet article présente une partie de l'étude du projet Cyberbullying - un diagnostic de la situation au Portugal, où un questionnaire a été appliqué à 3525 adolescents du collège $\left(6^{\mathrm{e}}\right.$ et $\left.4^{\mathrm{e}}\right)$ et du lycée (seconde) pour comprendre l'incidence du phénomène et pour analyser les processus associés, y compris les raisons, qui est l'objet spécifique de cet article. En ce qui concerne les raisons, les plus invoquées par ceux qui jouent le rôle de l'agresseur pour justifier leur comportement, sont celles hédonistes de plaisanterie, d'amusement et de fuite à l'ennui ainsi que d'affiliation et de représailles. Ceux qui s'identifient comme des victimes attribuent à leurs agresseurs les raisons d'affiliation, hédonistes et de pouvoir, avec un accent particulier (par l'ordre décroissant), sur l'envie, l'amusement, l'immaturité, la jalousie, le manque de respect, d'affection et les sentiments de supériorité.

Mots-clés: Cyber intimidation. Victimes. Intimidateurs. Raisons réactives. Raisons instrumentales.

\section{Introdução}

A

pesar dos esforços no campo da educação e das preocupaçóes globais com os direitos humanos, as sociedades contemporâneas ainda não conseguiram erradicar a violência e enfrentam, hoje, suas novas formas, que, em parte, resultam do progresso tecnológico alcançado. A Organização Mundial de Saúde/WHO (2002, p. 4) define a violência como a "utilização intencional de poder ou força física, na forma efectiva ou de ameaça, contra si próprio, contra outra pessoa, ou contra um grupo ou comunidade, da qual resulte ou possa resul- 
tar, com grande probabilidade, morte, dano físico e psicológico, perturbação do desenvolvimento ou privação".

A maioria dos autores (e.g., ANDERSON \& BUSHMAN, 2002; COSTA, 1986) consideram que a violência consiste em uma agressão com intenção deliberada de causar mal ao outro, sendo essa intenção percebida pelo autor, pela vítima ou mesmo por algum observador. Toda violência seria agressão, mas nem toda agressão seria violência.

O bullying é uma das múltiplas manifestaçóes de agressão e de violência entre pares, com especial incidência em meio escolar. Mas, para podermos caracterizar um ato como tal, devemos encontrar nele algumas caraterísticas muito próprias. De facto, a natureza específica e a prevalência do bullying começaram a ser estudadas empiricamente nos anos 1970, sendo de destacar a obra de Dan Olweus. Segundo esse autor, estamos diante de uma manifestaçáo de bullying em contexto escolar quando um aluno "se encontra exposto, de forma repetida e ao longo do tempo, a açóes negativas por parte de um ou mais alunos" (OLWEUS, 2005, p. 9). Trata-se, portanto, de atos sistemáticos de violência física, vexame emocional ou exclusão social. A incapacidade — física ou psicológica —, por parte da vítima, de dar uma resposta suscetível de reequilibrar a situação - o que também se designa como "assimetria ou desequilíbrio de poderes" — e a repetição premeditada desses atos ao longo de certo tempo são os principais critérios que permitem diferenciá-los de outras manifestaçôes de agressão e violência.

Apesar da maior consciencializaçáo sobre o problema do bullying e dos muitos projetos postos em marcha para preveni-lo e combatê-lo, verifica-se que o fenómeno não só persiste como tem evoluído para diferentes e novas práticas tornadas possíveis por meio do uso e abuso das novas Tecnologias da Informação e Comunicação (TIC). Atualmente, pode-se falar da existência de duas grandes categorias de bullying: o bullying face a face - também designado como presencial ou tradicional - e o cyberbullying ou bullying eletrónico. Para além dos meios e das formas de expressão existem outras diferenças importantes entre o bullying face a face e o cyberbullying, das quais podemos citar o fácil anonimato de quem agride por meio das novas tecnologias, escondendo ou dissimulando a sua identidade. Essa situação gera facilmente sentimentos de impunidade no agressor e intensifica a vulnerabilidade da vítima (MCGUCKIN et al., 2012). Acrescente-se, ainda, que no cyberbullying se transcendem as fronteiras do espaço físico e do tempo, quer para a vitimaçáo, quer para a agressáo; e que o número de espectadores pode ser indeterminado e multiplicar-se numa série imparável de acessos à comunicação hostil e/ou incómoda.

Independentemente dessas diferenças significativas, há todo um conjunto de problemáticas comuns às duas modalidades e que a investigaçáo tem desenvolvido, tais como: os perfis e as emoçóes de vítimas e agressores, os motivos dos agressores, as consequências para os diferentes sujeitos envolvidos, a relação circular entre as duas categorias de bullying, e muitas outras. Neste texto vamos centrar-nos essen- 
cialmente nos motivos que levam determinados indivíduos ao envio de mensagens deliberada e intencionalmente destrutivas, hostis ou incómodas por meio das TIC — computadores com acesso à internet, telemóveis e os recentíssimos smartphones.

Definimos as seguintes questões de investigação, a serem aqui tratadas:

1. Que motivos impelem alguns adolescentes para a prática do cyberbullying?

2. Que diferenças existem entre os motivos dos adolescentes que agridem e os percebidos por aqueles que são vítimas?

3. Que relações se observam entre os motivos, o ano de escolaridade e o sexo?

4. Que relações existem entre os motivos e as emoçóes sentidas pelos adolescentes agressores?

\section{Agressão, motivos e cyberbullying}

No estudo, as componentes subjetiva e motivacional são inquiridas directamente, a fim de entender a experiência tanto das vítimas quanto dos agressores. Trata-se de uma análise das justificaçóes que esses indivíduos atribuem ao comportamento dos agressores.

Partimos de algumas teorias e pesquisas sobre agressão que distinguem os constructos que aqui nos interessa aprofundar, nomeadamente que diferenciam processos, motivos ou funçóes reativos e motivos ou funçóes proactivos ou instrumentais da agressão. A dimensão reativa da agressão tem raízes na teoria de Berkowitz sobre frustraçáa-zanga, enquanto a dimensão instrumental se reporta à teoria da aprendizagem social de Bandura. Por outro lado, Little et al. (2003) estudam o comportamento de agressão e classificam-no em dois tipos: uma forma aberta, correspondendo a comportamentos verbais e físicos, e uma forma relacional, que dificulta ou até mesmo impede os sentimentos de inclusão, por meio de processos de rejeição, ostracismo, rumores contra terceiros etc. Quanto às funçóes desempenhadas pela agressão, distinguem entre agressóes reativas — correspondendo a comportamentos defensivos, de zanga e retaliação a situaçôes percepcionadas como provocaçôes, frustraçôes, hostilidades e ameaças — e instrumentais — que premeditadamente antecipam resultados que servem os objetivos dos próprios agressores. Os testes efetuados pelos investigadores supracitados demonstram independência entre formas/tipos de agressão e funções, por um lado, e entre funçóes reativas e instrumentais, por outro. Os estudos de Poulin e Boivin (2000) também mostram que essas funçôes correspondem a constructos relacionados, mas distintos. Essas diferentes funçōes estariam associadas a diferentes situaçóes e prediçóes. A interpretação de situaçóes ambíguas como hostis poderá ser preditor de comportamentos de agressão reactiva, e esta, por sua vez, estaria associada a emoçóes como a raiva e os sentimentos de rejeiçáo e baixa autoestima. Por outro lado, estudos longitudinais apontam para uma relação entre agressão instrumental e o desenvolvimento em jovens adolescentes de comporta- 
mentos de delinquência e criminalidade, ou, noutros casos e por contraste, com o desenvolvimento da liderança e competência social (idem).

Ainda em termos conceptuais, distinguiremos nesses motivos instrumentais, entre motivos de afiliação e motivos de poder, à semelhança de Roland e Idsøe (2001), embora introduzamos outros tipos de motivos — de diversão (à semelhança de Gradinger, Strohmeier e Spiel, 2012, e de Raskauskas \& Stoltz, 2007), todos autores que investigaram os motivos relacionados ao bullying e ao cyberbullying. Nesses estudos mais específicos os resultados mostram relaçóes significativas com a idade e o sexo.

O estudo de Gradinger, Strohmeier e Spiel (2012) aponta para a importância de categorizar os sujeitos agressores levando em consideração as situaçóes em que se envolvem. No estudo, os dados revelam uma sobreposição do cyberbullying ao bullying tradicional e da agressão à vitimização. Mostram, ainda, que para os cyber agressores, os motivos de retaliação são os mais recorrentes, seguidos do divertimento, e que os motivos de poder e afiliação não ocorrem com tanta frequência, o que os difere dos agressores de bullying tradicional, para os quais os motivos que se salientam são os de retaliação, e dos agressores que combinam ambos os tipos de bullying, para os quais a retaliação, como também o divertimento, o poder e a afiliação, são frequentes. A importância da retaliação em todos os casos confirma padrôes de comportamento em pré-adolescentes, como foi o caso deste estudo — realizado com 1.466 jovens entre 10 e 15 anos.

Em 2010, König, Gollwitzer e Steffgen desenvolveram um estudo com 473 estudantes para analisar se a vingança e a retaliação servem como motivos para o envolvimento em atos de cyberbullying. Procuraram, ainda, identificar se as vítimas de bullying tradicional que posteriormente se tornam agressores de cyberbullying escolhem os seus agressores de bullying como alvos, o que foi constatado no estudo.

Por seu lado, o estudo de Raskauskas e Stoltz (2007) aponta para a importância do divertimento na perspectiva dos agressores. Esses motivos estão também associados ao nível de ensino, à idade e ao sexo. Por exemplo, Roland e Idsøe (2001) verificaram que no oitavo ano havia relação positiva com motivos de poder e afiliação, mas não com reacçóes de raiva, enquanto todos esses motivos eram significativos no quinto ano, e que a afiliação surgia com mais relevância nas raparigas, enquanto para os rapazes se destacavam motivos associados ao poder sobre o outro. No mesmo sentido, os estudos de Gradinger, Strohmeier e Spiel (2012), Little et al. (2003) e Roland e Idsøe (2001) salientam a incidência de motivos de poder e de divertimento nos rapazes. Quanto à variável sexo, encontramos resultados controversos nos estudos de Roland e Idsøe (2001) e de Little et al. (2003). Enquanto os primeiros observaram que os motivos de afiliação apresentam maior incidência nas raparigas, os segundos constataram que são os rapazes que mais referem esses tipos de motivos.

Por outro lado, alguns dos estudos sobre motivos e emoçóes são associados a referenciais teóricos ligados ao desenvolvimento e à cognição moral. Os resultados tendem a apontar para um raciocínio hedonístico e egocêntrico por 
parte dos agressores, pelo que o prazer é mais importante que o sofrimento das vítimas (MENESINI et al., 2003). No mesmo sentido, alguns estudos referem que os agressores náo atribuem motivos hostis a si próprios, deslocam a sua responsabilidade para terceiros e têm expectativas positivas sobre os resultados do seu comportamento (PERREN et al., 2012; PORNARI \& WOOD, 2010). Trata-se de formas de desresponsabilização e desinvestimento moral, com tendência para serem mais frequentes no raciocínio dos rapazes do que no das raparigas (idem). Esse é um referencial que tem por base a teoria de descomprometimento moral de Bandura (2002), entendido como um conjunto de "processos cognitivos através dos quais a pessoa é capaz de cometer atos horríveis contra os outros" (HYMEL, ROCKE-HENDERSON \& BONANNO, 2005, p. 2), sendo o foco direcionado mais aos ganhos pessoais e às sançóes do que aos assuntos morais. Bandura refere quatro processos psicológicos de descomprometimento moral:

1. reestruturação cognitiva, como dar justificaçóes morais, etiquetar eufemisticamente, comparar com comportamentos piores;

2. obscurecer ou minimizar o seu próprio papel, deslocando ou diluindo a sua responsabilidade;

3. distorcer ou desvalorizar o impacto do comportamento; e

4. culpar e desumanizar a vítima.

No estudo de Hymel, Rocke-Henderson e Bonanno (2005), realizado com adolescentes e no qual se utilizou um questionário de autorrelato, os investigadores verificaram, à semelhança do estudo de Menesini et al. (2003), relação positiva entre agressão no bullying e raciocínios de descomprometimento moral, quer nos agressores, quer nas vítimas com taxas moderadas de bullying. Os autores consideram que se trata de formas mais benignas de descomprometimento, na medida em que as estratégias usadas vão no sentido de distorcer o impacto sobre as vítimas e considerar que estas mereciam a agressão. Também no estudo de Menenisi et al. (2003), os agressores, mais do que as vítimas, referiam explicaçóes egocêntricas, contemplando consequências e vantagens pessoais, bem como emoçôes de descomprometimento moral como a indiferença e o orgulho.

No presente estudo são considerados motivos hedonistas os relacionados com brincadeira, diversão e fuga ao tédio - como não ter nada para fazer e estar aborrecido. Motivos de afiliação, relacionais e afetivos também são estudados — relativos aos afetos, ao ciúme, à inveja. Identificamos também motivos instrumentais associados ao poder sobre o outro, diferenças e divergência de opinióes. Ligando com as dimensôes do controlo e valor, e com a agressão reativa, estudaremos em particular os motivos morais invocados ou transgredidos - entre os quais o de justiça retributiva como vingança e retaliação face a agressão anterior e a falta de respeito. 


\section{Metodologia da investigação}

Como foi dito, este estudo faz parte de um projecto de investigação mais amplo, que se desenrolou em duas etapas: na primeira usou-se um questionário com perguntas de resposta aberta, enquanto na segunda procedeu-se a um estudo extensivo com aplicação de um questionário com perguntas de resposta mista. É nessa última fase que se inscreve o estudo aqui apresentado.

\section{Instrumento de investigação e procedimentos de recolha e de análise}

A partir da análise dos dados da primeira etapa do projecto, foi construído pela equipa de investigação um questionário, que inclui quatro partes distintas. No início do questionário é dada uma explicação sobre o que é cyberbullying ${ }^{3}$, de forma que os participantes possam responder com base em uma definição comum. Seguem-se questóes destinadas a caracterizar a amostra em termos sociodemográficos e questôes genéricas sobre a utilizaçâo das novas tecnologias. A segunda parte é constituída por conjuntos de questōes que visam recolher informaçóes sobre os jovens no papel de vítima, enquanto a terceira reúne dados sobre os jovens no papel de agressor. Nessas duas partes do questionário incluem-se perguntas sobre as emoçóes e os sentimentos experienciados e sobre os motivos para os atos de cyberbullying (ver exemplo de pergunta na Tabela 1).

Finalmente, a quarta parte do questionário é constituída por questóes com as quais se pretende perceber os apoios a que os jovens recorrem nessas situações, incluindo uma escala de ambiente escolar e outra de ambiente familiar.

\section{Tabela 1}

Exemplo de pergunta do questionário: 32. Por que motivo(s) fizeste isso? (assinala com uma cruz até três opções).

\begin{tabular}{l|l}
\hline 32.1. Falta de respeito & 32.9. Por ciúmes \\
\hline 32.2. Por inveja & 32.10. Quebra de amizades \\
\hline 32.3. Divergência de opinióes & 32.11. Por não gostar dele \\
\hline 32.4. Para me divertir & 32.12. Por vingança \\
\hline 32.5. Por estar aborrecido & 32.13. Por me sentir superior \\
\hline 32.6. Por não ter nada para fazer & 32.14. Por imaturidade \\
\hline 32.7. Por brincadeira & 32.15. Não sei \\
\hline $\begin{array}{l}\text { 32.8. Por diferenças entre nós (culturais, cor } \\
\text { da pele, sexuais etc.) }\end{array}$ & $\begin{array}{l}\text { 32.16. Porque eles me tinham agredido física } \\
\text { ou verbalmente }\end{array}$ \\
\hline 32.17. Outro motivo. Qual? &
\end{tabular}


O questionário foi aplicado presencialmente com a colaboração de professores das respectivas escolas, muitos dos quais tinham participado de um curso de formação na modalidade b-learning - Violência e Gestão de Conflitos na Escola, financiado pelo Ministério da Educação — , promovido pela equipa de investigadores do projeto. Foram cumpridas todas as formalidades e acçóes necessárias e exigidas a uma investigação rigorosa e ética, incluindo o consentimento informado dos jovens participantes e dos pais dos menores.

Como temos vindo a referir, neste artigo apresentamos os resultados da análise relativos aos motivos que levam à prática do cyberbullying, relacionando-os com as emoçóes e os sentimentos experimentados e com algumas variáveis demográficas. Para além das análises estatísticas de carácter descritivo, foram utilizados testes inferenciais, como os testes de $\chi^{2}$, correlação de Spearman e bynary logistic regression.

\section{Amostra}

O questionário foi aplicado em 23 agrupamentos de escolas e escolas situadas nas regióes norte, centro e sul do país. Recolheram-se 3.525 respostas de alunos do ensino básico e secundário (6º $8^{\circ}$ e $11^{\circ}$ anos). A amplitude etária vai dos 10 aos 23 anos de idade, sendo a moda 13 anos e a média 13,6, com desvio-padrão 2,3. Os valores da mediana situam-se, para ambos, nos 13 anos.

No que respeita às respostas às questóes sobre a experiência pessoal enquanto agressor e enquanto vítima, são muito menos as respostas recolhidas. De entre os participantes no estudo, 138 (3,9\%) reconheceram-se como tendo estado envolvidos, no último ano, em situaçóes nas quais tiveram comportamento de agressor - ofensa, difamação, ameaça, perseguição de alguém por meio de telemóvel ou internet - e 267 (7,6\%) responderam assumindo terem sido vítimas desse tipo de comportamento. A Tabela 2 apresenta a distribuição de vítimas e de agressores na amostra, segundo os níveis de escolaridade e o sexo.

\section{Tabela 2}

Distribuição da amostra por nível de escolaridade e sexo.

\begin{tabular}{c|c|c|c|c|c|c}
\hline & \multicolumn{3}{|c|}{ Vítimas } & \multicolumn{3}{c}{ Agressores } \\
\cline { 2 - 7 } & M & F & Total & M & F & Total \\
\hline $6^{\circ}$ ano & 28 & 33 & 61 & 14 & 4 & 18 \\
\hline $8^{\circ}$ ano & 29 & 50 & 79 & 23 & 16 & 39 \\
\hline $11^{\circ}$ ano & 43 & 83 & 126 & 45 & 36 & 81 \\
\hline Total & 100 & 166 & $266^{*}$ & 82 & 56 & 138 \\
\hline
\end{tabular}

M: masculino; F: feminino; *um participante não revelou o ano de escolaridade. 
Como se pode verificar na Tabela 2, são mais as raparigas (166) e os alunos do $11^{\circ}$ ano (126) que se identificam como vítimas, e mais os rapazes (82) e também os alunos do $11^{\circ}$ ano (81) que se identificam como agressores.

\section{Resultados: motivações no cyberbullying}

\section{$\underline{\text { Motivos dos agressores }}$}

A Tabela 3 mostra o conjunto dos resultados sobre os motivos invocados pelos agressores.

De entre os motivos invocados pelos agressores sobressaem motivos hedonistas e egoicos relacionados com brincadeira $(34,1 \%)$, diversão $(28,8 \%)$ e ainda com fuga ao tédio, que apontam no sentido de usar o cyberbullying por não ter nada para fazer $(17,4 \%)$ ou estar aborrecido $(15,9 \%)$. Motivos de afiliação, que parecem ter uma função instrumental como "não gostar dele" (22,7\%), ou parcialmente reactiva e instrumental, como a quebra de amizades (17,4\%), são outros motivos relevantes.

Questóes morais de justiça retributiva e de agressão reativa, como vingança $(21,2 \%)$, retaliação face a agressão anterior $(14,4 \%)$ e falta de respeito $(13,6 \%)$, surgem também com alguma expressão, apontando para comportamentos reativos, como resposta a provocaçóes anteriores.

\section{Tabela 3}

Motivos invocados pelos agressores.

\begin{tabular}{|c|c|c|}
\hline & Total & Total $(\%)$ \\
\hline \multicolumn{3}{|l|}{ Motivos hedonistas e egoicos } \\
\hline Brincadeira & 45 & 34,1 \\
\hline Diversão & 38 & 28,8 \\
\hline Fuga ao tédio & 23 & 17,4 \\
\hline Estar aborrecido & 21 & 15,9 \\
\hline \multicolumn{3}{|l|}{ Motivos de afiliação } \\
\hline Não gostar dele & 30 & 22,7 \\
\hline Quebra de amizades & 23 & 17,4 \\
\hline \multicolumn{3}{|l|}{ Motivos morais } \\
\hline Vingança & 28 & 21,2 \\
\hline Retaliação & 19 & 13,6 \\
\hline Falta de respeito & 18 & 14,4 \\
\hline \multicolumn{3}{|c|}{ Motivos conflituais e sentimentos de superioridade } \\
\hline Diferenças & 1 & 0,8 \\
\hline Divergência de opiniōes & 14 & 10,6 \\
\hline Sentimentos de superioridade & 5 & 3,8 \\
\hline
\end{tabular}


Questôes conflituais relativas à diferença $(0,8 \%)$, à divergência de opiniôes $(10,6 \%)$ ou a sentimentos de superioridade $(3,8 \%)$ parecem ter muito menos expressão. Parece, assim, haver pouca consciência de alguns factores instrumentais relacionados, como o poder que se quer exercer.

Comparação entre motivos dos agressores, reconhecidos por eles próprios e atribuídos pelas vítimas

A Tabela 4 sintetiza o conjunto dos dados relativos aos motivos dos agressores, reconhecidos por eles próprios e atribuídos pelas vítimas.

Usando o teste $\chi^{2}$, emergem apenas dois motivos em que há significância estatística, pelo que apenas em dois motivos os respondentes são coerentes quando estão na posição de vítimas e agressores, na atribuição de motivos aos agressores: por brincadeira $\left(\chi^{2}(\right.$ g.l. $\left.)=5,054, \mathrm{p}<0,05\right)$ e por quebra de amizades $\left(\chi^{2}\right.$ (g.l. $\left.)=7,2, p<0,05\right)$.

Destacam-se distinçôes entre atribuiçóes de motivos aos agressores, em que as vítimas tendem a enfatizar mais motivos relacionais e de afiliação, como inveja $(39,4 \%)$, ciúme $(28,3 \%)$ e falta de respeito $(25,3 \%)$; associados à comparação social; motivos pessoais associados à imaturidade $(34,2 \%)$ e motivos associados à necessidade de poder dos agressores sobre as vítimas $(24,9 \%)$.

\section{Tabela 4}

Motivos dos agressores, reconhecidos por eles e atribuídos pelas vítimas.

\begin{tabular}{l|c|c|c|c}
\hline Motivos dos agressores & $\begin{array}{c}\text { Reconhecidos } \\
\text { pelos agressores } \\
\mathbf{( \% )}\end{array}$ & $\begin{array}{c}\text { Atribuí-dos } \\
\text { pelas vítimas } \\
\mathbf{( \% )}\end{array}$ & $\begin{array}{c}\text { Teste do } \\
\chi^{2}\end{array}$ & Sig. \\
\hline Por brincadeira & 34,1 & 13,8 & 5,054 & $0,045^{*}$ \\
\hline Para me divertir & 28,8 & 33,1 & 0,001 & 0,60 \\
\hline Por náo gostar dele & 22,7 & 24,9 & 0,018 & 0,588 \\
\hline Por vingança & 21,2 & 9,7 & 1,270 & 0,247 \\
\hline Por quebra de amizades & 17,4 & 15,2 & 7,200 & $0,022^{*}$ \\
\hline Por năo ter nada para fazer & 17,4 & 20,4 & 0,529 & 0,349 \\
\hline Por estar aborrecido & 15,9 & 6,7 & 2,870 & 0,150 \\
\hline Por falta de respeito & 13,6 & 25,3 & 0,166 & 0,57 \\
\hline Por divergência de opinióes & 10,6 & 5,2 & 4,986 & 0,082 \\
\hline Por ciúmes & 9,1 & 28,3 & 2,584 & 0,124 \\
\hline Por imaturidade & 9,1 & 34,2 & 0,005 & 0,668 \\
\hline Náo sei & 6,8 & 10,0 & 0,035 & 0,668 \\
\hline Por me sentir superior & 3,8 & 24,9 & 0,508 & 0,667 \\
\hline Por inveja & 2,3 & 39,4 & 0,890 & 0,53 \\
\hline
\end{tabular}

Sig.: significance. 
Por seu lado, e em comparação, os agressores enfatizam, mais do que as vítimas, motivos reativos, como vingança $(21,2 \%)$, e motivos associados a divertimento, como o aborrecimento (15,9\%).

Assim, a autoimagem dos agressores e a imagem que as vítimas têm deles parecem indicar, da parte dos primeiros, uma autojustificação, desculpabilização e desvalorização do seu comportamento, enquanto os segundos apontam para motivos que reprovam moralmente e que associam parcialmente à necessidade de controlar os outros.

\section{Relação entre motivos e variáveis sociodemográficas}

Com base na utilização do coeficiente de Spearman, é possível analisar os motivos em que é significativa a correlação com idade, nível de escolaridade e sexo.

No que respeita à relação entre os motivos dos agressores, a idade e o nível de escolaridade, os testes de significância apontam que os agressores de nível de escolaridade mais baixo tendem a referir a inveja $(r=0,229 ; \mathrm{p}<0,01)$ e a vingança $(r=0,188 ; p<0,05)$, e o inverso acontece a motivos ligados à diversão $(r=-0,260$; $\mathrm{p}<0,01)$ e ao aborrecimento $(\mathrm{r}=-0,195 ; \mathrm{p}<0,05)$, significativamente mais referidos pelos agressores de nível de escolaridade mais elevado.

No que respeita ao sexo, não há diferenças significativas relativas a nenhum motivo dos agressores, a não ser o aborrecimento, no caso dos rapazes $(\mathrm{r}=0,206 ; \mathrm{p}<0,05)$, e os motivos de quebra de amizades $(\mathrm{r}=-0,171 ; \mathrm{p}<0,05)$ e por não gostar do outro $(\mathrm{r}=-0,193 ; \mathrm{p}<0,05)$, no caso das raparigas, à semelhança de outros estudos sobre bullying que sugerem uma maior importância das relaçóes, e, por consequência, da rejeição, nas raparigas (BANDEIRA \& HUTZ, 2012).

\section{Relação entre motivos e emoções dos agressores}

$\mathrm{Na}$ relação entre motivos e emoções dos agressores verificam-se algumas relações estatisticamente significativas — usando função de regressão logística que procura relaçóes de causalidade —, como indicado na Tabela 5 - em que todas as relaçóes apresentadas são significativas.

Verifica-se, pois, uma coerência entre o que é desejado e o que é conseguido, nomeadamente a presença de emoçóes de prazer e satisfação em situaçóes em que os motivos explicitados pelos agressores envolviam o divertimento e a brincadeira ou situaçóes em que não tinham nada para fazer. Realça-se aqui a dimensão hedonista presente na perpretação de atos de cyberbullying. 
Tabela 5

Emoções e motivos dos agressores.

\begin{tabular}{|c|c|c|c|c|}
\hline & $\mathbf{B}$ & S.E. & Wald & Sig. \\
\hline \multicolumn{5}{|l|}{ Satisfação } \\
\hline Não ter nada para fazer & 1,400 & ,640 & 4,784 & ,029 \\
\hline Não gostar dele & 1,123 & ,496 & 5,129 &, 024 \\
\hline Constant & 34,465 & 80386,071 &, 000 & 1,000 \\
\hline \multicolumn{5}{|l|}{ Prazer } \\
\hline Não ter nada para fazer & 3,011 & ,847 & 12,641 &, 000 \\
\hline Quebra de amizades & 1,776 & ,744 & 5,699 &, 017 \\
\hline Constant & 37,185 & 80386,096 &, 000 & 1,000 \\
\hline \multicolumn{5}{|l|}{ Tristeza } \\
\hline Brincadeira & $-3,045$ & 1,484 & 4,208 &, 040 \\
\hline Constant & 117,578 & 94482,834 & ,000 & ,999 \\
\hline \multicolumn{5}{|l|}{ Zanga } \\
\hline Para me divertir & 3,589 & 1,332 & 7,254 &, 007 \\
\hline Quebra de amizades & $-3,077$ & 1,501 & 4,201 &, 040 \\
\hline Imaturidade & 2,962 & 1,194 & 6,157 & ,013 \\
\hline Porque me tinham agredido & 3,695 & 1,388 & 7,089 & ,008 \\
\hline Constant & 48,543 & 87263,804 &, 000 & 1,000 \\
\hline \multicolumn{5}{|l|}{ Alívio } \\
\hline Porque me tinham agredido & 1,291 & ,646 & 3,994 & 046 \\
\hline Constant & 84,914 & 87449,455 &, 000 & ,999 \\
\hline \multicolumn{5}{|l|}{ Sentir-se mais forte } \\
\hline Vingança & 1,880 & ,723 & 6,772 & ,009 \\
\hline Constant & 71,417 & 83102,364 &, 000 & ,999 \\
\hline \multicolumn{5}{|l|}{ Indiferença } \\
\hline Porque me tinham agredido & $-2,153$ & 1,074 & 4,017 &, 045 \\
\hline Constant & 86,549 & 87988,696 & ,000 & ,999 \\
\hline \multicolumn{5}{|l|}{ Diversão } \\
\hline Para me divertir & 2,664 & ,854 & 9,721 & 002 \\
\hline Brincadeira & 2,225 & 856 & 6,762 & ,009 \\
\hline Constant & 4,839 & 92909,735 &, 000 & 1,000 \\
\hline \multicolumn{5}{|l|}{ Vontade de não ver ninguém } \\
\hline Falta de respeito & 2,889 & 1,219 & 5,621 & ,018 \\
\hline Ciúmes & 3,135 & 1,320 & 5,644 & ,018 \\
\hline Não sei & 3,849 & 1,867 & 4,251 & 039 \\
\hline Constant & 112,354 & 99055,433 & ,000 & ,999 \\
\hline \multicolumn{5}{|l|}{ Culpa } \\
\hline Brincadeira & 2,670 & 1,060 & 6,340 & 012 \\
\hline Náo sei & 2,728 & 1,292 & 4,459 &, 035 \\
\hline Constant & 11,434 & 91598,966 & , 000 & 1,000 \\
\hline
\end{tabular}

B: B test; S.E: standard error; Wald: Wald Test; Sig.: significance. 
Verifica-se, por outro lado, entre os resultados significativos estatisticamente, alguma polaridade emocional para alguns dos motivos evocados pelos agressores, nomeadamente:

- na quebra de amizades, em que as emoções associadas à agressão são o prazer e a zanga;

- quando o ciúme provoca atos de agressão, as emoçóes associadas são de alívio ou vontade de não ver ninguém.

Quando os agressores atuam por terem sido anteriormente agredidos, as emoçóes associadas aos atos de cyberbullying ora são neutras, de indiferença, ora ativas e negativas, de zanga, ora positivas e passivas, de alívio. Também é positivo o sentir-se mais forte, em situações nas quais o motivo é a vingança.

É de notar que a emoção de zanga é a que surge significativamente associada a um maior leque de motivos, parecendo apontar para situaçóes de retaliação face a agressóes anteriores ou perda de amizades, mas também nos casos de relação com o motivo de diversão, podendo significar uma dissonância cognitiva que se tenta resolver pela procura de coerência entre emoção — zanga — e ato — agressão.

\section{Discussão e pistas para a intervenção}

Para além da importância e diferente incidência que diversos motivos parecem ter na experiência de cyberbullying, quer no papel de vítimas, quer no papel de agressores, os dados indicam disparidade entre os motivos dos agressores reconhecidos por eles próprios e pelas vítimas, algumas diferenças significativas de acordo com o sexo e o nível de escolaridade e, ainda, algumas relaçóes significativas entre emoçôes e motivos dos agressores.

Sobressaem, nos dados fornecidos pelos que se reconheciam no papel de agressores, motivos hedonistas e egoicos relacionados com brincadeira, diversão e fuga ao tédio (à semelhança de estudos como os de Raskauskas \& Stoltz (2007) e de Martins (2013)), envolvendo não apenas situações de agressão face a face, mas também questóes de agressão reativa, de vingança e retaliação face a agressão anterior, indo ao encontro de resultados de outros investigadores (e.g., GRADINGER; STROHMEIER; SPIEL, 2012; MARTINS, 2013; ROLAND \& IDSØE, 2001; SALMIVALLI \& NIEMENEN, 2002). Questôes relacionais e de afiliação constituem outra categoria de motivos relevantes - como acontecia no estudo de Gradinger, Strohmeier e Spiel (2012), para os pré-adolescentes que combinavam, simultaneamente, o papel de agressor no bullying tradicional e no cyberbullying. Questôes de poder e protagonismo social são menos frequentes, como também se verificou no estudo de Gradinger, Strohmeier e Spiel (2012), e contrariamente ao que sucede 
em estudos de agressão face a face quando se avaliam as explicaçóes das vítimas e de observadores para os comportamentos de agressão (MARTINS, 2013).

Não se pretendendo, à partida, na elaboração do questionário, o aprofundamento das justificações para pesquisar a presença da dimensão moral, é possível, no entanto, equacionar algumas interpretaçôes a este nível, relacionando os resultados com os de outros estudos que se debruçaram sobre esses aspectos. Efectivamente, a presença forte de motivos hedonistas e as justificaçóes de reatividade com base na retaliação parecem apontar para um pensamento egocêntrico e estratégias de descomprometimento moral, tais como culpabilizar a vítima e deslocar a sua responsabilidade e etiquetar eufemisticamente o seu comportamento, associando-o à diversão (BANDURA, 2002). Também a análise da relação entre motivos e emoções dos agressores vem reforçar essa interpretação, ao enfatizar a dimensão hedonista e de descomprometimento moral. Aqui importa fazer uma reflexão que, extrapolando os dados de que dispomos, aponta para fatores sociais e culturais de ordem mais ampla, que importará aprofundar noutros estudos, que extravasem os motivos invocados pelos próprios. A prevalência de motivos hedonistas, associados a emoçóes de prazer e de divertimento, e os possíveis processos de descomprometimento moral são coerentes com uma sociedade de consumo, dominada por uma ideologia liberal e por uma economia capitalista globalizada, assente no máximo lucro em curto prazo. Sociedade na qual os jovens, por um lado, vivem a ilusão da abundância ilimitada associada à oferta de estimulaçóes e prazeres múltiplos e, por outro, sentem a impotência para encontrar um lugar onde possam fazer a diferença e perspetivar alternativas societais. Vivemos na sociedade do fast food e do descartável, em que também as relaçóes são pautadas pela fluidez, fragmentação e efemeridade (BAUMAN, 2007). As novas geraçôes de nativos tecnológicos, a que alguns também chamam milénios, vivem grande parte do tempo mergulhadas nas redes sociais, buscando muitas vezes o prazer imediato, o prazer pelo prazer, a felicidade instantânea, cultivando a superficialidade, o simulacro e o parecer ser, que retira sentido, profundidade e consistência ao seu desenvolvimento, com consequências a muitos níveis e particularmente no seu desenvolvimento comunicacional, moral e ético. Embora estejam a aumentar, por contraposição, movimentos e estruturas de participação dos jovens na sociedade em prol de causas sociais, muito ainda precisa ser feito para uma real e massiva consciência social que se possa contrapor à cultura dominante. A sociedade em geral — designadamente os jovens com os seus educadores — precisa implicar-se seriamente na construção do presente e do futuro, integrando as potencialidades, as incertezas e os desafios que a contemporaneidade nos coloca. Não desperdiçando a inovação, importa assumir o princípio da responsabilidade pelo futuro da humanidade (JONAS, 2006) aos mais diferentes níveis — saúde, ambiente, educação, tecnologias etc. - e cultivar nas relaçôes humanas uma pragmática universal apoiada na intercompreensão, que, segundo Habermas, constitui o imperativo categórico da pós-modernidade (RUSS \& LEGUIL, 2012, p. 31). 
Retomando os dados do nosso estudo, os estudantes, em função de seu papel desempenhado - de vítima ou de agressor —, têm perceção diferente dos motivos do cyberbullying. As vítimas tendem a enfatizar motivos instrumentais, de afiliaçẫo e de poder, como inveja, ciúme, falta de respeito e o sentir-se superior, e motivos pessoais, como imaturidade. Por seu lado, e em comparaçáo, os agressores enfatizam, mais do que as vítimas, motivos reativos, como vingança e retaliação de agressão, e motivos de diversão, como brincadeira e fuga ao tédio. Esses dados são coerentes com outros estudos, como o de Sanders, Smith e Cillessen (2011), segundo o qual se destacam a inveja e os problemas de aceitação pelos pares, nomeadamente nas raparigas, e também a vingança. Por contraposição, nesse estudo a brincadeira e a diversão parecem ser muito menos frequentes do que na nossa amostra. Também o estudo de Gradinger, Strohmeier e Spiel (2012), centrado nos agressores e nos agressores-vítimas em bullying tradicional e cyberbullying, aponta no sentido de uma presença mais forte de motivos reativos e de divertimento do que de poder e afiliação. As diferenças de perceção entre agressores e vítimas podem significar que estas têm dificuldade em perceber os motivos daqueles; que observam dimensóes que os agressores não identificam em si próprios; que se desculpabilizam, atribuindo a eles emoçóes amorais como inveja e ciúmes; ou que os desculpabilizam, considerando-os imaturos. Também podem significar que os agressores têm dificuldade de se julgar ou de assumir socialmente seus motivos instrumentais, não reconhecendo o carácter premeditado e o desejo de causar mal aos outros. Esses dados podem estar associados a dimensóes morais, com descomprometimento dos que agridem e julgamento moral dos que são agredidos. Por outro lado, a insegurança e o desejo de evitar estáo muito presentes quando as vítimas atribuem a agressão à quebra de amizades e à divergência de opinióes. Em todo caso, sobressai o sofrimento das vítimas, e a indiferença é apenas associada significativamente à atribuição, pelas vítimas, a motivos como brincadeira e aborrecimento dos agressores.

Em relação ao sexo, os dados apontam para diferenças significativas a favor das raparigas em motivos instrumentais de afiliação, e a favor dos rapazes em motivos ligados ao divertimento, o que vem ao encontro de outros estudos (BANDEIRA \& HUTZ, 2012; GRADINGER; STROHMEIER; SPIEL, 2012; ROLAND \& IDSØE, 2001), embora outros apontem noutros sentidos, nos quais a afiliação surge mais associada aos rapazes mais velhos (e.g., LITTLE et al., 2003), ou os factores de poder sobressaem nos rapazes (ROLAND \& IDSØE, 2001), mesmo que o divertimento também seja significativamente mais importante para eles do que para as raparigas (ROLAND \& IDSØE, 2001, LITTLE et al., 2003).

No que respeita ao nível de ensino, nosso estudo salienta motivos reativos e de afiliação, como a inveja, nos mais jovens, enquanto os motivos ligados à diversão são significativamente mais referidos pelos mais velhos. Mais uma vez, esses resultados são parcialmente coerentes com alguns estudos, como o de Roland e Idsøe (2001), segundo o qual é menos forte a relação entre agressão reativa nos 
alunos mais velhos e mais forte a agressão proactiva, como é o caso dos motivos de afiliação, enquanto nos alunos mais jovens há relação positiva com ambos os tipos de agressão - esse último aspecto também se verifica no estudo de Salmivalli \& Niemenen, 2002.

Assim, os resultados evidenciados neste estudo sugerem que a divisão entre agressão reactiva e instrumental, enquanto funções diferenciadas da agressão em contextos face a face, é também uma classificação pertinente aos contextos "virtuais". Essa classificação parece associar-se aos diferentes motivos invocados pelos adolescentes, isto é, divertimento e brincadeira para agressóes proactivas ou instrumentais, e vingança, raiva e retaliação para agressóes reactivas, à semelhança do que os estudos em contexto face a face haviam encontrado (DODGE et al., 1997).

Tendo em conta os motivos identificados, quer pelos que se referem como vítimas, quer pelos que se referem como agressores, é preciso equacionar uma intervenção que procure prevenir o cyberbullying e algumas de suas causas, mas também quebrar o ciclo da violência que, por vezes, se desenvolve em ambos os sentidos.

Importa apoiar crianças, adolescentes e jovens, criando ambientes favoráveis para encontrarem os sentidos e os projetos que os façam motivar-se no sentido construtivo e participativo, encontrando a si próprios e aos outros, por meio de relaçóes e afetos que os façam sentir-se valorizados e realizados, no pleno desenvolvimento dos seus dons. Trata-se, pois, de formar cidadáos conscientes, eticamente responsáveis, capazes de transmutar suas emoçóes negativas em motivaçôes e ações transformadoras. Nascido na relação, o cyberbullying precisa ser trabalhado também na relação, sobretudo quando os próprios sentem que, juntos, têm capacidade de controlo sobre as situaçóes. Tanto ou mais do que coordenar esforços, é preciso agregar empenhamentos e o envolvimento no diálogo e nos afetos, como antídotos para a violência e para o medo. Mesmo sabendo que causas sociais mais indiretas estáo presentes, cabe também aos atores sociais, enquanto sujeitos com capacidade de resistência e transformação, o dever de atuar para que as organizaçóes e as relaçóes sejam espaços de construção, aprendizagem e expressão do que há de melhor em cada um.

\section{Referências}

ANDERSON, C.; BUSHMAN, B. Human aggression. Annual Review of Psychology, v. 53, p. 27-51, 2002.

BANDEIRA, C.; HUTZ, C. Bullying: prevalência, implicaçôes e diferenças entre os gêneros. Psicologia Escolar e Educacional, Campinas, v. 16, n. 1, p. 35-44, jan./jun. 2012. Disponível em: <http://www.scielo.br/pdf/pee/v16n1/04.pdf>. Acesso em: 2 ago. 2013. 
BANDURA, A. Selective moral disengagement in the exercise of moral agency. Journal of Moral Education, v. 31, n. 2, p. 101-119, ago. 2002.

BAUMAN, Z. A vida fragmentada: ensaios sobre a moral pós-moderna. Lisboa: Relógio d'Água, 2007.

COSTA, J. F. Violência e psicanálise. Rio de Janeiro: Graal, 1986.

DODGE, K.; LOCHMAN J. E.; HARNISH J. D.; BATES J. E.; PETTIT, G. S. Reactive and proactive aggression in school children and psychiatrically impaired chronically assaultive youth. Journal of Abnormal Psychology, Washington, v. 106, n. 1, p. 37-51, fev. 1997.

GRADINGER, P.; STROHMEIER, D.; SPIEL, C. Motives for Bullying Others in Cyberspace. In: LI, Q.; CROSS, D.; SMITH, P. K. (Orgs). Cyberbullying in the Global Playground: Research from International Perspectives. Oxford: Wiley-Blackwell, 2012. p. 263-284.

HYMEL, S.; ROCKE-HENDERSON, N.; BONANNO, R. Moral disengagement: a framework for understanding bullying among adolescents. Special international issue on victimization. Journal of Social Sciences, v. 8, p. 1-11, 2005.

JONAS, H. O princípio responsabilidade: ensaio de uma ética para a civilização tecnológica. Rio de Janeiro: Contraponto; Ed. PUC-Rio, 2006.

KÖNIG, A.; GOLLWITZER, M.; STEFFGEN, G. Cyberbullying as an act of revenge? Australian Journal of Guidance and Counselling, v. 20, p. 210-224, dez. 2010.

LITTLE, T. D.; HERINCH, C. C.; JONES, S. M.; HAWLEY, P. H. Disentangling the "whys" from the "whats" of aggressive behavior. International Journal of Behavioral Development, v. 27, n. 2, p. 122-133, mar. 2003.

MARTINS, M. J. D. Problemas relacionais na escola: explicaçôes e sentimentos dos adolescentes. In: SERPA, M.; CALDEIRA, S.; GOMES, C. (Orgs.). Resolução de problemas em contexto escolar. Lisboa: Colibri, 2013. p. 85-106.

MCGUCKIN, C. et al. Introdução ao cyberbullying. In: JÄGER, T.; STELTER, C.; AMADO, J.; MATOS, A.; PESSOA, T. (Orgs.). Cyberbullying: um manual de formação de pais. p. 78-107. Landau: Verlag Empirische Pädagogik, 2012. Disponível em: <http:// ct4p.zepf.eu/CT4P Training manual PT.pdf >. Acesso em: 25 ago. 2013.

MENESINI, E.; SANCHEZ, V.; FONZI, A.; ORTEGA, R.; COSTABILE, A.; LO FEUDO, G. Moral emotions and bullying: a cross-national comparison of differences between bullies, victims and outsiders. Aggressive Behavior, Malden, v. 29, n. 6, p. 515-530, dez. 2003.

OLWEUS, D. Bullying at school: what we know and what we can do. Oxford: Blackwell Publishing, 2005.

ORGANIZAÇÃO MUNDIAL DA SAÚDE (WHO). World report on violence and health. Summary. Geneva, 2002. Disponível em: $\leq$ http://www.who.int/publications/en/>. Acesso em: 26 mar. 2007. 
PERREN, S.; GUTZWILLER-HELFENFINGER, E.; MALTI, T.; HYMEL, S. Moral reasoning and emotion attributions of adolescent bullies, victims, and bully-victims. British Journal of Developmental Psychology, Malden, v. 30, n. 4, p. 511-530, nov. 2012.

PORNARI, C. D.; WOOD, J. Peer and cyber aggression in secondary school students: the role of moral disengagement, hostile attribution bias, and outcome expectancies. Aggressive Behavior, Malden, v. 36, n. 2, p. 81-94, mar.-abr. 2010.

POULIN, F; BOIVIN, M. Reactive and proactive aggression: evidence of a two-factor model. Psychological Assessment, v. 12, n. 2, p. 115-122, jun. 2000.

RASKAUSKAS, J.; STOLTZ, A. D. Involvement in traditional and electronic bullying among adolescents. Developmental Psychology, v. 43, n. 3, p. 564-575, maio 2007.

ROLAND, E.; IDSØE, T. Aggression and bullying. Aggressive Behavior, Malden, v. 27, n. 6, p. 446-462, nov. 2001.

RUSS, J.; LEGUIL, C. La pensé éthique contemporaine. Paris: PUF, 2012.

SALMIVALLI, C.; NIEMENEN, E. Proactive and reactive aggression among school bullies, victims, and bully-victims. Aggressive Behavior, Malden, v. 28, n. 1, p. 30-44, 2002.

SANDERS, J. B. P.; SMITH, P. K.; CILLESSEN, A. H. N. All about cyberbullies: who they are and what they do. 2011. Disponível em: <http://www.education.com/reference/ article/cyberbullies-who-they-are-what-do/>. Acesso em: 22 mar. 2011.

Recebido em 10 de setembro de 2014.

Aprovado em 03 de fevereiro de 2017. 